\title{
Estimate of maintenance energy requirements of Salers beef cows during mid-pregnancy
}

\author{
M Petit, P Kabré, J Agabriel \\ INRA, laboratoire Lactation et Élevage des ruminants, centre de Clermont-Theix, \\ 63122 Saint-Genès-Champanelle, France
}

Twenty-one Salers nearly-mature $(4-7 \mathrm{yr}$ old) non-lactating cows were used during mid-pregnancy (from the 2nd to the 7th month) to estimate their maintenance energy requirements. They were allocated for $156 \mathrm{~d}$ to 1 of the 3 following treatments: $75(\mathrm{H}), 63(\mathrm{M})$ or $52(\mathrm{~L})) \mathrm{g}$ dry matter (DM) per $\mathrm{kg}$ initial metabolic live-weight (LW0.75) and per $\mathrm{d}$ of a diet composed of $95 \%$ hay and a $5 \%$ mixture of soya bean meal and barley. Minerals were added. The hay contained $309 \mathrm{~g}$ crude fiber and $22 \mathrm{~g} \mathrm{~N}$ per $\mathrm{kg}$ DM.

The cows were housed in an unheated stable (between $5-15^{\circ} \mathrm{C}$ ) in tying stalls. Initial $\mathrm{LW}$ and body condition score (BCS) were $588 \mathrm{~kg}$ and 1.8 (on a 5-unit scale) respectively. Changes in LW (averaged for 2 successive days) and BCS (averaged for 2 operators) were obtained between the ends of a pre- and post-experimental period of 2 wk during which all cows received the H-diet. Corrected LW (CLW) were calculated by deducting the weights of conceptus estimated from fetuses' ages and calves' birth weights (INRA, 1988). Net energy intake (ex- pressed as net energy for lactation, NEL) was estimated from the digestibility of energy observed on $3 \mathrm{H}$-cows $(0.64)$ and $3 \mathrm{~L}$-cows $(0.61)$. NEL available for maintenance and maternal energy gain or loss (NEL maint) was calculated by deducting NEL for pregnancy (INRA, 1988) from NEL intake.

Changes in LW, CLW and BCS differed between treatments (table I). Relationships between NEI maint and CLW change or BCS change obtained for all cows were highly significant ( $r=0.88$ and 0.73 respectively). Maintenance requirements were estimated on corresponding principal axes for either no change in CLW or no change in BCS: 60 or $58 \mathrm{kcal}$ NEL (100 or $97 \mathrm{kcal}$ ME) per $\mathrm{kg}$ CLW 0.75 respectively. These values were in accordance with those published previously in the literature. The slopes of the principal axes were used as estimates of the changes in NEL intake per kg CLW gained (9.5 Mcal NEL or 15.8 Mcal ME) or per unit change in BCS ( 318 Mcal NEL or 530 Mcal ME).

Table I. Changes in weight and condition score of pregnant Salers cows fed different levels of energy.

\begin{tabular}{lccc}
\hline & \multicolumn{3}{c}{ NEL intake/LWo.75 } \\
\cline { 2 - 4 } & 67 & 83 & 99 \\
\cline { 2 - 4 } & & & \\
\hline & $44^{\mathrm{a}}$ & $69^{\mathrm{b}}$ & $97^{\mathrm{c}}$ \\
Change in LW (kg) & $0^{\mathrm{a}}$ & $22^{\mathrm{b}}$ & $51^{\mathrm{c}}$ \\
Change in conceptus-free LW (kg) & $0.2^{\mathrm{a}}$ & $0.8^{\mathrm{ab}}$ & $1.4^{\mathrm{b}}$ \\
Change in BCS (unit) & & & \\
\hline
\end{tabular}

Values on the same line with different letters in superscript are significantly different $(P<0.05)$. 